\title{
Second Century Defences around Small Towns in Roman Britain Structured by Road
}

\section{Network Connectivity}

\section{Abstract}

The large-scale provision of defences around small towns in Roman Britain during the second century is without parallel in the Roman Empire. Whilst the relationship between defended small towns and the Roman road network has been noted previously, provinciallevel patterns remain to be explored. Using network analysis and spatial inference methods, this paper shows that defended small towns in the second century are on average better integrated within the road network, as well as located on road segments important for controlling the flow of information, than small towns at random. This research suggests that the fortification of small towns in the second century was structured by the connectivity of the Roman road network and the functioning of the cursus publicus.

\section{Key words}

Network Analysis; Roman Britain; Small Towns; Hypothesis Testing; Connectivity; Road Network

\section{Introduction}

The provision of defences around towns in Roman Britain has attracted interest since the $1930 s^{1}$, with the general outline well established: in the first century, the provision of defences was limited to a few public towns (coloniae, municipium, civitas capitals) ${ }^{2}$; in the second century, a large number of earthwork defences were erected in public towns, as well as in settlements subordinate to civitas capitals in political and administrative status (henceforth small towns) ${ }^{3}$; in the third century, more small towns received walls; and finally, in the fourth century, external towers were added to existing walls ${ }^{4}$.

Whilst it should be noted that the issue of defining a 'small town' continues to be debated ${ }^{5}$, with the selection and subdivision based on characteristics such as function or

\footnotetext{
${ }^{1}$ Hobley 1983, 78

${ }^{2}$ Frere $1984 b$

${ }^{3}$ Burnham and Wacher 1990; Wacher 1975

${ }^{4}$ Frere 1984a

${ }^{5}$ Booth 1998; Rust 2006; Todd 1970
} 
origin common ${ }^{6}$, small towns differ from civitas capitals in several ways: they often lacked official administrative status, planned rectangular street grids, and key public facilities such as a forum and bathhouses ${ }^{7}$. Although the presence of small towns is common to all provinces of the Roman Empire ${ }^{8}$, the large-scale provision of defences around small towns in Roman Britain - whether during or after the second century - is without parallel ${ }^{9}$. Fortification of small towns in neighbouring provinces such as Gaul, Germany, and Raetia remained rare, with defences often limited to settlements with civitas status ${ }^{10}$. Due to this, Esmond-Cleary suggests that small towns from the second century onwards played a more significant role within the civitates and Roman Britain more generally compared to other provinces $^{11}$.

Traditionally, the motivation to construct defences around towns has been driven by two hypotheses: (1) a centralised government response to an actual or perceived threat ${ }^{12}$; (2) or a symbol of civic pride initiated by local authorities ${ }^{13}$. Whilst civic pride and display is considered a plausible explanation for defences around higher-status towns (coloniae, municipium, civitas capitals) ${ }^{14}$, the significant number of small towns defended in the second century remains more difficult to explain ${ }^{15}$. For example, the defence of small towns has been related to specific periods of historical upheaval ${ }^{16}$, such as the usurpation of Clodius Albinus (193-197). However, the use of 'external threat' as the explanatory model has become less tenable as defences show chronological phasing, as well as the more general issue of fitting archaeological evidence into historical narratives ${ }^{17}$. Furthermore, whilst the motivation of civic pride has been used as an explanation for the provision of defences

\footnotetext{
${ }^{6}$ e.g. Burnham 1986; Burnham and Wacher 1990

${ }^{7}$ Millett 1990, 144-45; Todd 1970; Wacher 1975

${ }^{8}$ Ligt and Bintliff 2020 for an overview

${ }^{9}$ Esmond-Cleary 2003

${ }^{10}$ Esmond-Cleary 2007

${ }^{11}$ Esmond-Cleary 2003

${ }^{12}$ Frere 1984a; Wacher 1975, 75

${ }^{13}$ Millett 1990, 139-40

${ }^{14}$ Esmond-Cleary 2007

${ }^{15}$ Esmond-Cleary 2003; Esmond-Cleary 2007

${ }^{16}$ e.g. Frere 1991, 241; Wacher 1962

${ }^{17}$ Esmond-Cleary 2007
} 
47 around small towns ${ }^{18}$, Esmond-Cleary notes that this is "no more than a possibility and does

little to explain the fortification of the 'small towns"19.

In contrast, the defence of small towns has been linked to important installations, such as the mansiones and mutationes that were integral for the development and functioning of the Roman provincial transportation system (cursus publicus) ${ }^{20}$. Through the cursus publicus, government communication was made possible: essential for securing and maintaining control throughout the empire ${ }^{21}$. Nonetheless, this led Smith and Fulford to ask: "if the common factor linking defended settlements on the major roads was that they supported the cursus publicus [...], why were not all such settlements provided with defences?"22. With this question in mind, this research will use network analysis and spatial inference methods to identify provincial-level patterns in the relationship between small towns fortified in the second century and the connectivity of the Roman road network.

Namely, two testable hypotheses will be investigated:

(1) Defended small towns were well integrated within the road network for the efficient transfer of information;

(2) Defended small towns were located on roads that were important for controlling the flow of information across the road network;

\section{Materials and Methods}

The data and code are available at https://github.com/josephlewis/Defended Small Towns.

\section{Roman Road Network}

The Roman road network was downloaded from Bishop ${ }^{23}$. Based on Roman roads identified by Margary ${ }^{24}$, this dataset represents the most comprehensive Roman Britain road network currently available. It should be noted, however, that knowledge of the Roman road

\footnotetext{
${ }^{18}$ Millett 1990, 137-40

${ }^{19}$ Esmond-Cleary 2007

${ }^{20}$ Black 1995; Burnham and Wacher 1990, 12-14; Esmond-Cleary 2007; Smith and Fulford 2019

${ }^{21}$ Kolb 2001; Haynes 2002

${ }^{22}$ Smith and Fulford 2019, 18

${ }^{23}$ Bishop 2014

${ }^{24}$ Margary 1973, 170
} 
network is currently incomplete ${ }^{25}$, with the region north of London showing a greater concentration of roads ${ }^{26}$. Whilst this reflects local interest in identifying Roman roads ${ }^{27}$, rather than the true distribution of Roman roads in Roman Britain, the impact on this on the analysis is outside the scope of this paper and will therefore not be further explored. To ensure that the Roman road network as currently understood was interconnected, and thus sufficient for network analysis, small gaps were manually fixed by connecting road ends via straight-lines (Fig. 1A). The choice to manually join roads - predominately to urban centres over other automated methods such as connecting all road ends within $500 \mathrm{~m}^{28}$ or least cost path analysis ${ }^{29}$ aimed to minimise the introduction of additional uncertainty ${ }^{30}$. The road network was converted to a network graph, with road vertices acting as nodes and road segments as edges (Fig. 1B).
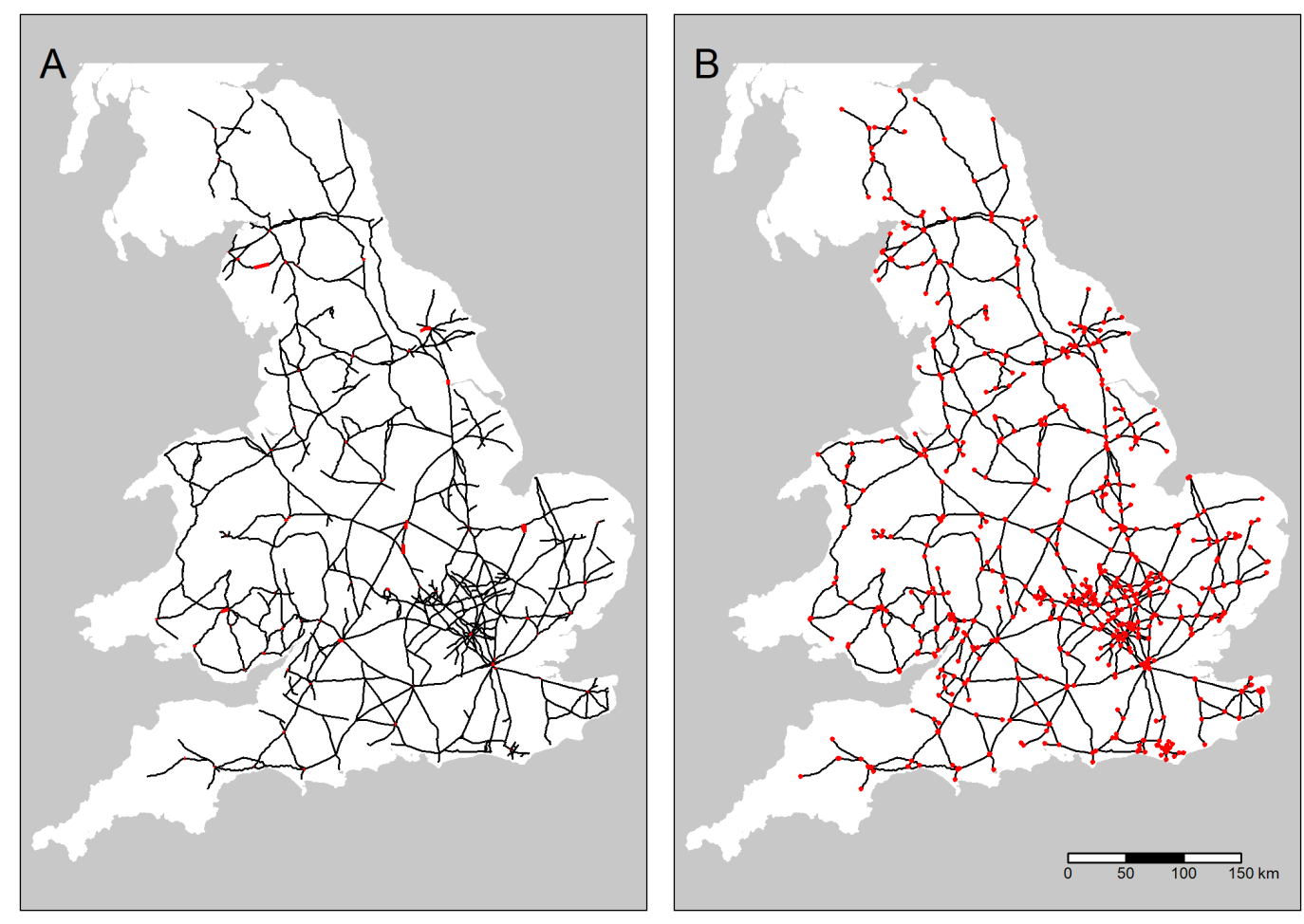

Figure 1. Roman roads in Roman Britain based on Bishop (2014) (grey) with small gaps filled by present author (black) (A) and network graph representation of the Roman road network with vertices acting as nodes and road segments as edges (B)

\footnotetext{
${ }^{25}$ estimated to be $40 \%$ at best by the Roman Roads Research Association 2021

${ }^{26}$ Margary 1973

27 e.g. The Viatores 1964

${ }^{28}$ e.g. Brookes and Huynh 2018

${ }^{29}$ e.g. Orengo and Livarda 2016

${ }^{30}$ e.g. Lewis 2021
} 
Data on 90 small towns with sufficient information on the date of defences was collated from Millett ${ }^{31}$, using Smith and Fulford for more accurate chronologies when possible ${ }^{32}$. Four small towns (Brough-on-Fosse, Dorn, Dropshot, and Sandy Lane) were removed from the analysis due to uncertainty in the dates of fortification ${ }^{33}$. Nonetheless, the large number of small towns included within the analysis aims to sufficiently represent small towns as a category. The 90 small towns were filtered to those within $1 \mathrm{~km}$ from the Roman road network, ensuring that the small towns were deemed to be sufficiently integrated within the road network. The remaining 79 small towns were used within the analysis, with 22 (28\%) defended in the second century. The small towns were subsequently attached to the Roman road network graph to become nodes (Fig. 2).

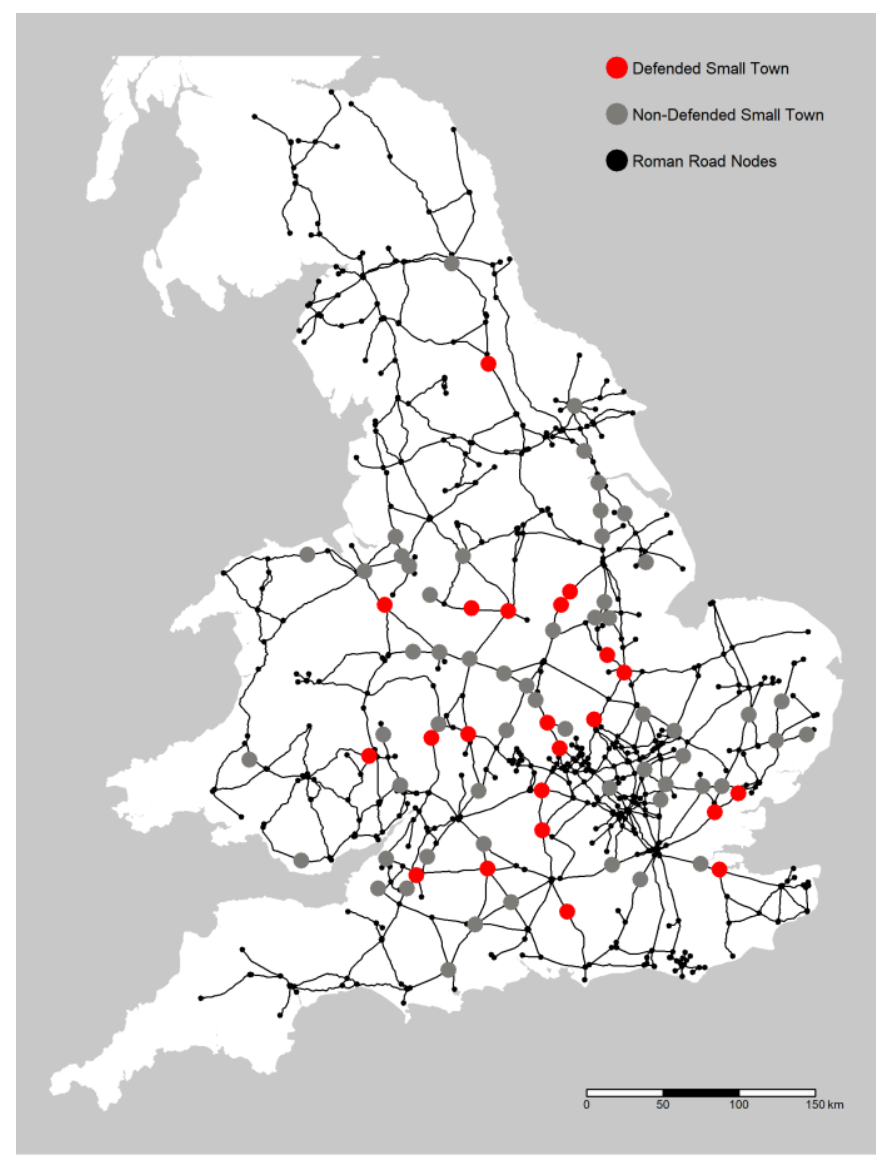

Figure 2. Roman roads with second century defended and non-defended small towns as nodes

\footnotetext{
${ }^{31}$ Millett 1990, 154-56

${ }^{32}$ Smith and Fulford 2019

${ }^{33}$ Ibid.
} 

underlying spatial distribution of small towns' ${ }^{41}$.

\section{Network Analysis Measures}

\section{Nodal Efficiency}

The application of network analysis to archaeological research has rapidly increased ${ }^{34}$. By representing data as a network graph, with nodes signifying points and edges representing the connections between them, the fundamental characteristics of a network structure at a node- and network-level can be analytically described ${ }^{35}$. For example, Pau de Soto assessed the accessibility of the Iberian Peninsula using the Roman road network ${ }^{36}$; Orengo and Livarda analysed the circulation of goods in relation to Roman Britain road network properties $^{37}$; and Brookes and Huynh assessed the correlation in town PageRank values to their status in Roman and early medieval England ${ }^{38}$.

Whilst less common in archaeology, the network representation of archaeological data can also be used in the formal testing of hypotheses ${ }^{39}$. More specifically, the significance of a spatial pattern - in this case, whether defended small towns were well integrated within the road network and located on Roman roads important for controlling the flow of information - can be quantified by randomly reshuffling the characteristic of interest, whilst keeping all other aspects of the data not relevant to the hypothesis constant ${ }^{40}$. Through this, the underlying process of interest and whether it resulted in the spatial pattern can be evaluated, or more simply put: "how likely is it that the observed spatial pattern of defended small towns has arisen from a random process given the

The efficiency of defended small towns for communication was measured via nodal efficiency. Nodal efficiency is the inverse of the average length of the minimum path length

\footnotetext{
${ }^{34}$ Brughmans and Peeples 2017

35 Brughmans 2010; Gorenflo and Bell 1991; Verhagen, Nuninger and Groenhuijzen 2019

${ }^{36}$ de Soto 2019

37 Orengo and Livarda 2016

38 Brookes and Huynh 2018

39 Östborn and Gerding 2014

${ }^{40}$ Good 2005

${ }^{41}$ modified from Fotheringham and Brunsdon 2004
} 
between a given node and all other nodes in the network ${ }^{42}$ (Fig. 3). Nodes with high nodal efficiency are well integrated within the overall network and indicate a higher capability of transferring information efficiently to all other nodes ${ }^{43}$. The nodal efficiency of all small towns was calculated, with the nodal efficiency of defended small towns mean averaged.

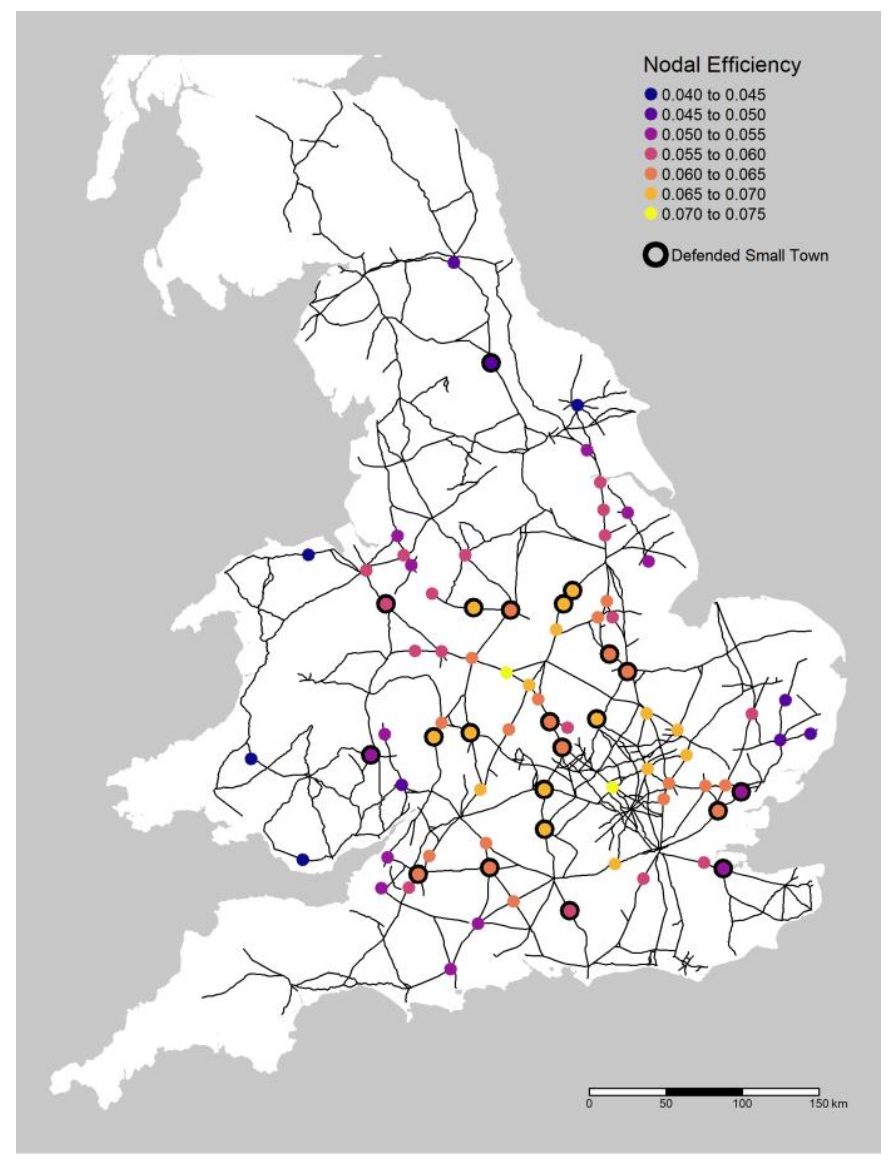

Figure 3. Nodal efficiency of defended (black border) and non-defended small towns (nonblack border)

\section{Edge Betweenness}

The importance of a road segment for controlling the flow of traffic was measured via edge betweenness. Edge betweenness is the number of shortest paths in the graph that pass through a given edge ${ }^{44}$. Edges with high edge betweenness thus control the flow of information and act as 'bridges' between multiple parts of the network ${ }^{45}$ (Fig. 4). The edge

\footnotetext{
42 Latora and Marchiori 2001

43 Ibid.; Latora and Marchiori 2003

${ }^{44}$ Freeman 1978

45 Ibid.
} 
betweenness of all road segments was calculated, with the edge betweenness of roads with defended small towns situated along them mean averaged.

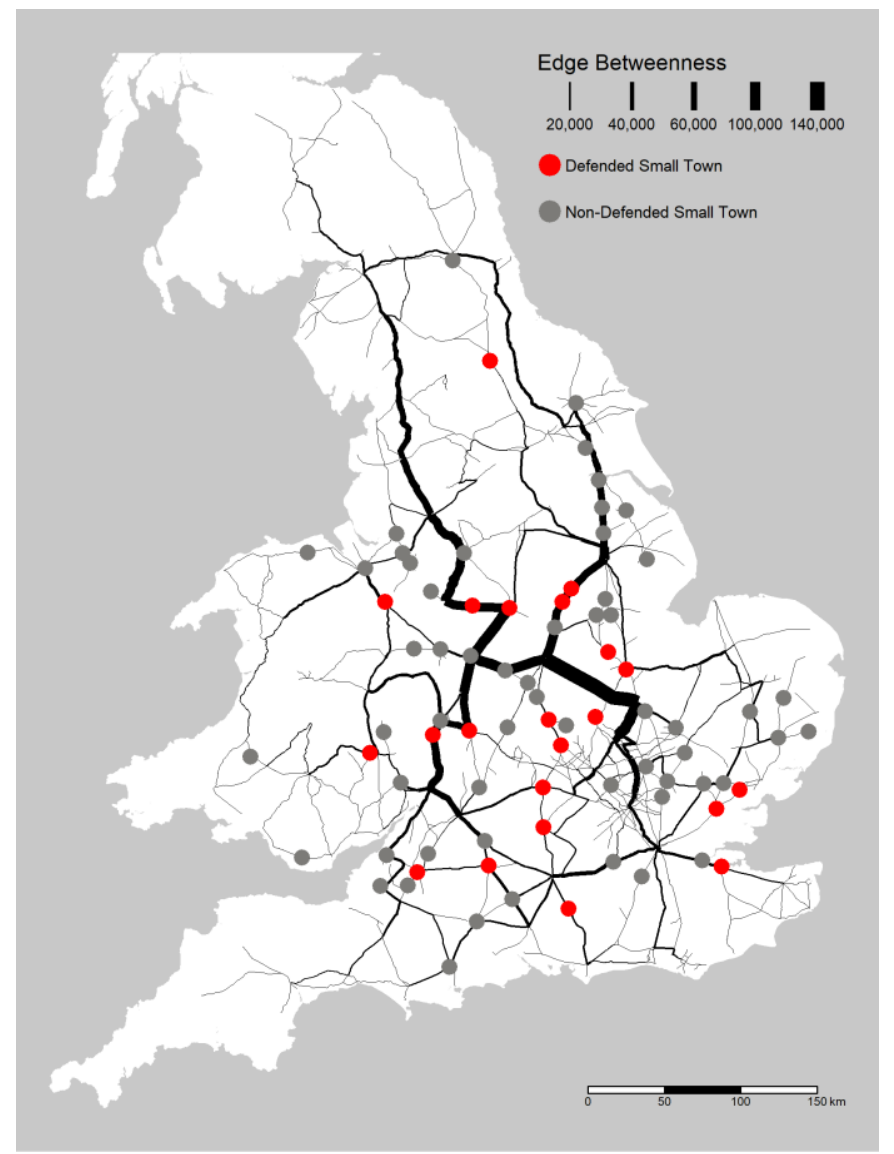

Figure 4. Edge betweenness of each road segment in the road network with defended small towns

The null hypothesis of mean nodal efficiency and mean edge betweenness was calculated by randomising the status of small towns - that is, randomly re-labelling whether a small town was 'defended' or 'non-defended' (Fig. 5). The randomisation in the status of the small towns reflects that of a random process ${ }^{46}$, with the rejection of the null hypothesis signifying that the observed pattern of defended small towns is unlikely to have occurred by chance. A one-sided Monte Carlo hypothesis test was used to statistically compare the mean nodal efficiency and mean edge betweenness of the observed pattern of defended small towns against 999 simulations where the 'defended' or 'non-defended' status of small towns was

${ }^{46}$ Fotheringham and Brunsdon 2004; Östborn and Gerding 2014 
randomised $(p<0.05)$. Whilst a relatively small number of simulations are required when using Monte Carlo hypothesis testing, with 99 simulations often sufficient ${ }^{47}, 999$ simulations results in a better estimate of the $p$-value ${ }^{48}$. Under a Monte Carlo hypothesis test procedure ${ }^{49}, N$ values of the test statistic (e.g. mean nodal efficiency) from simulations under the null hypothesis (where status is randomised) are compared to the observed statistic (where status is not randomised), with the p-value obtained by counting the number $m$ of simulated test statistics at least as extreme as the observed test statistic ( $p$ value $=(m+1) /(N+1))^{50}$.
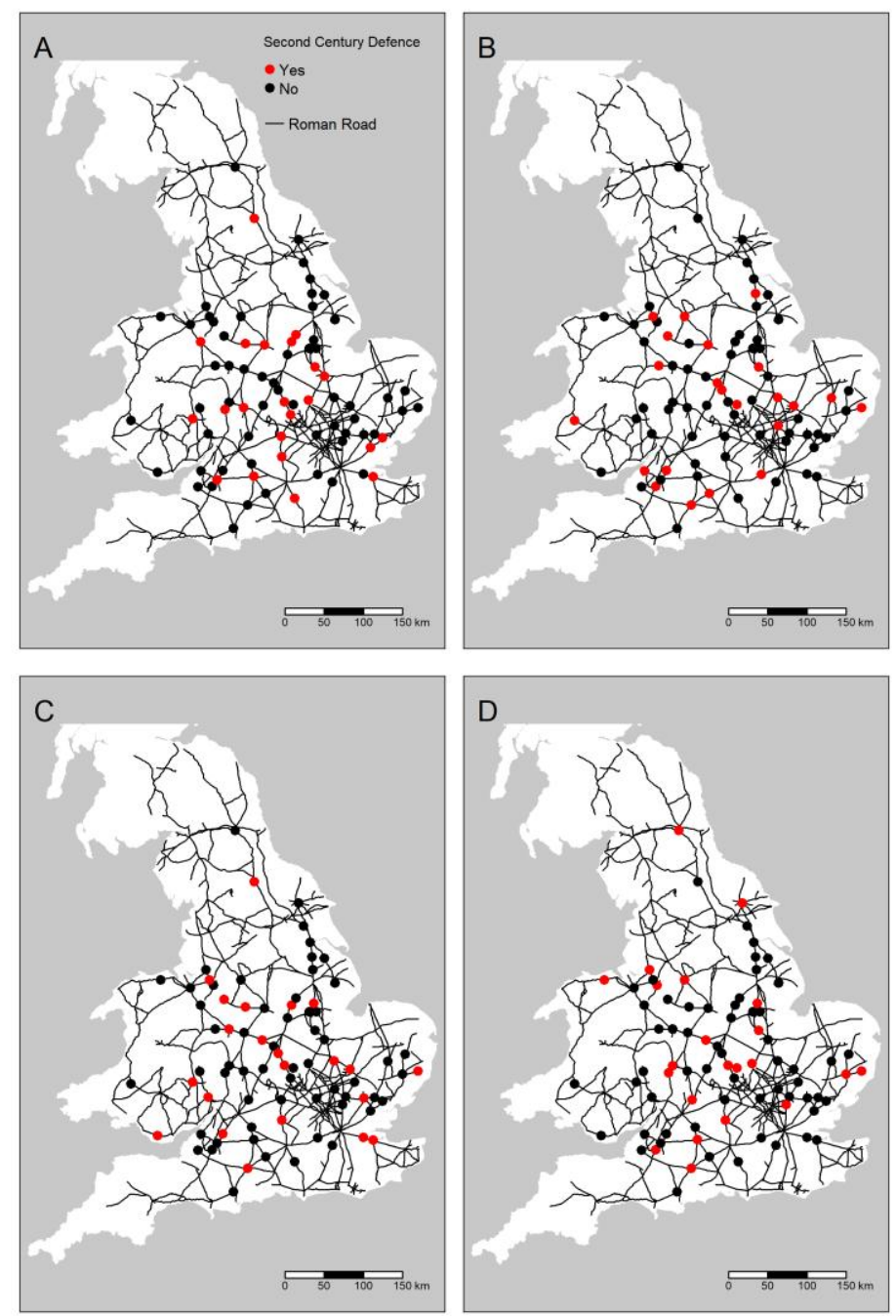

Figure 5. Roman road network with observed distribution of small towns (A) and examples after randomly shuffling the 'defended' status of small towns (B, C, and D)

\footnotetext{
${ }^{47}$ Besag and Diggle 1977; Hope 1968

${ }^{48}$ Gentle 2002, 55-57

${ }^{49}$ Barnard 1963

${ }^{50}$ North, Curtis and Sham 2002; Turner and Jeffs 2017
} 
The mean nodal efficiency of the defended small towns is greater than non-defended small towns, with the defended small towns showing less variance in nodal efficiency values (Fig. 6A). Furthermore, the mean edge betweenness of road segments with defended small towns is greater than road segments with non-defended small towns (Fig. 6B).
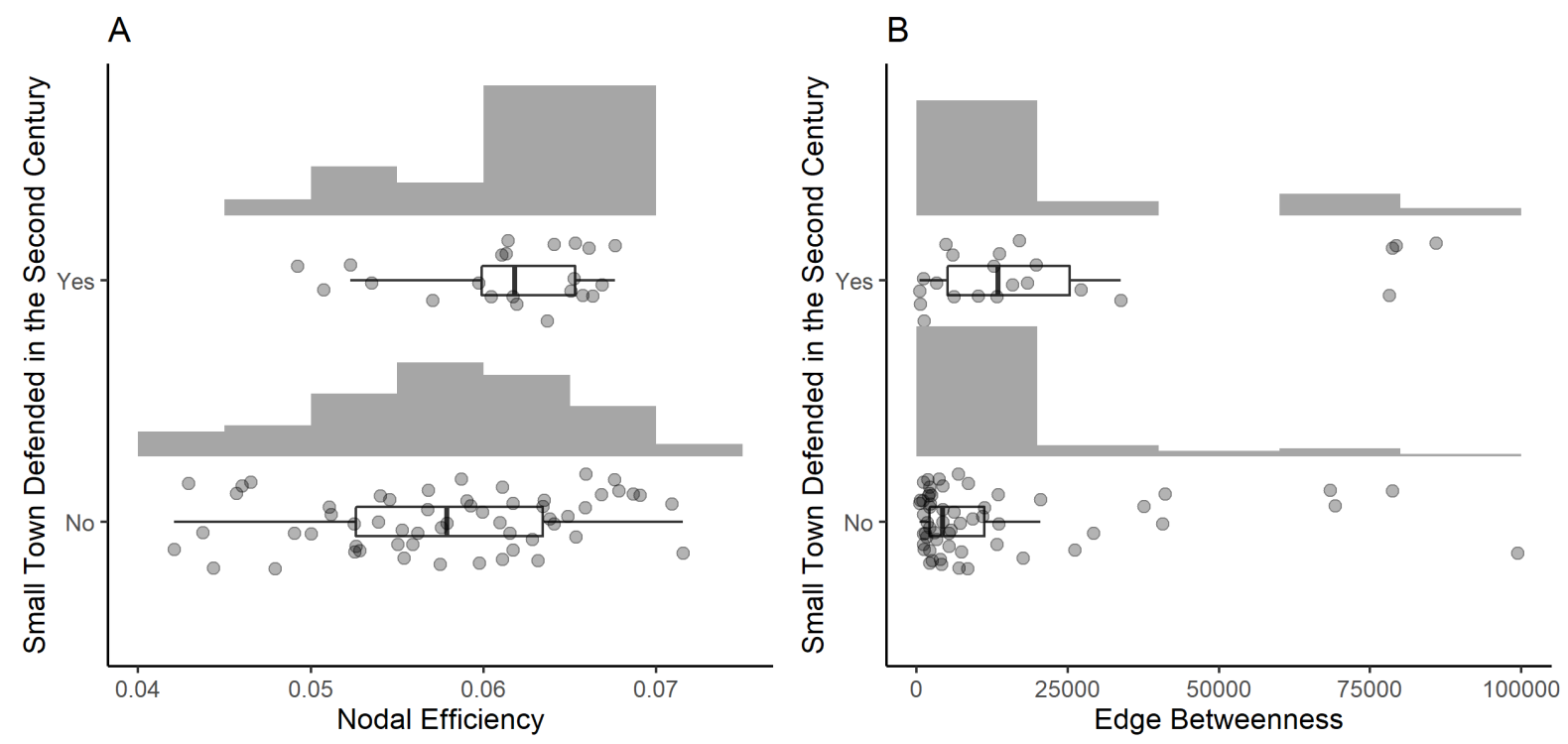

Figure 6. Nodal efficiency of defended and non-defended small towns (A) and edge betweenness of defended and non-defended small towns (A) Using the Monte Carlo hypothesis test procedure, the mean nodal efficiency of the 22 defended small towns is statistically significant $(p<0.05)$ compared to the 999 randomised simulations (Fig. 7A). This means that the defended small towns on average possess a higher capability of transferring information to other nodes, and thus more

172 integrated within the road network than small towns chosen at random. Similarly, the mean edge betweenness of road segments with defended small towns is statistically significant ( $p$ $<0.05)$ compared to the randomised simulations (Fig. 7B), showing that defended small towns were on average located on roads that had more control on the flow of information, whilst also acting as bridges to other parts of the Roman province. 

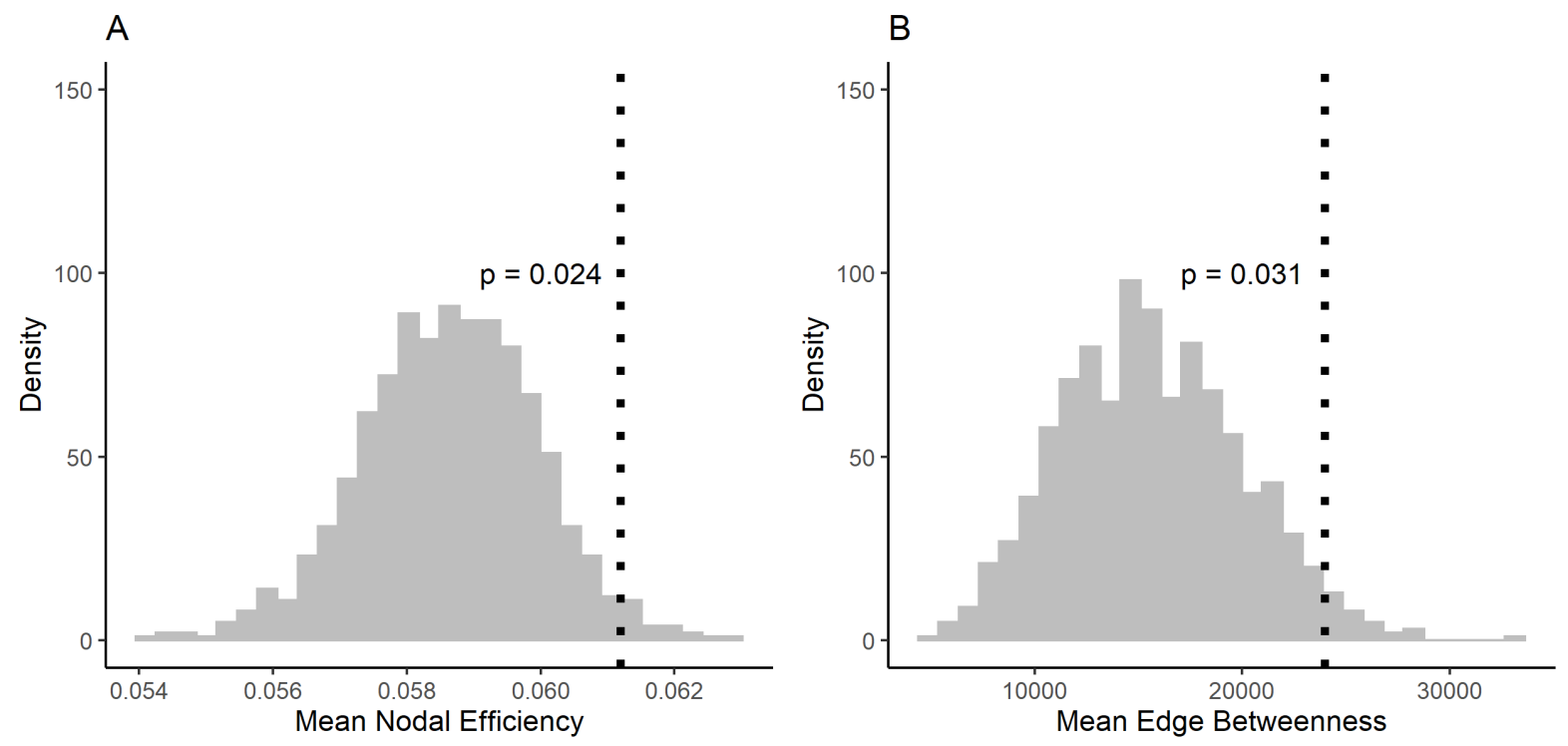

Figure 7. Distribution of mean nodal efficiency from randomised simulations and the true mean nodal efficiency of defended small towns (black dashed line) (A) and distribution of mean edge betweenness from randomised simulations and true mean edge betweenness of defended small towns (black dashed line) (B)

\section{Discussion and Conclusion}

Whilst the relationship between defended small towns and the Roman road network has been noted previously ${ }^{51}$, this research has shown that the connectivity of the Roman road network is associated with the fortification of small towns in the second century. Defended small towns in the second century on average possessed higher nodal efficiency as well as being located on roads with higher values of edge betweenness than non-defended small towns. Furthermore, the rejection of the null hypotheses shows that the small towns defended in the second century were on average better integrated within the road network than small towns at random, as well as being situated along road segments that were important for controlling the flow of information across the road network. Although the reason for fortifying small towns was complex and likely not due to a single cause ${ }^{52}$, the provincial-level pattern of defended small towns in the second century having high connectivity whilst also being well integrated within the road network echoes the fundamental role defended small towns played in the communication of information via the

\footnotetext{
51 e.g. Burnham and Wacher 1990, 235-78

${ }^{52}$ Esmond-Cleary 2003, 84
} 
cursus publicus ${ }^{53}$. This suggests that, as noted by Millett ${ }^{54}$, whilst civic competition between communities might have driven the provision of defences, government officials were keen to ensure that the defences also protected administrative infrastructure related to the functioning of the cursus publicus.

Nevertheless, it is important to be aware of limitations: firstly, the nodal efficiency and edge betweenness are based on the edges present within the road network. Whilst the impact of missing road segments, as well as filling in gaps using straight lines, is assumed to be minimal, it highlights the need for a more complete understanding of the road network in Roman Britain ${ }^{55}$. Secondly, this analysis ignores the possibility of maritime and river navigation, resulting in potentially undervaluing the nodal efficiency and edge betweenness for small towns and road segments near rivers and the coast. Whilst this effect is assumed to be small due to the majority of defended small towns being in the central belt of Roman Britain, future research is needed to incorporate multiple types of transportation when conducting provincial-level analyses ${ }^{56}$. Lastly, as the present analysis focused exclusively on small towns defended in the second century, there is a need to determine whether and how much the road network continued to have an influence on which small towns were fortified in later periods. network played a fundamental role in which small towns were defended during the second century. The provision of defences around small towns and the association with the protection of the administrative infrastructure therefore reflects the importance of the cursus publicus in the establishment and maintenance of Roman rule within the Roman province of Britannia.

\section{Declaration of Competing Interest}

The authors declare that they have no known competing financial interests or personal relationships that could have appeared to influence the work reported in this paper.

\footnotetext{
53 Black 1995; Smith and Fulford 2019

${ }^{54}$ Millett 1990, 140

55 e.g. Roman Roads Research Association 2021

56 e.g. Carreras and De Soto 2013; Carreras, De Soto and Muñoz 2019
} 


\section{References}

Barnard, G.A. 1963. "Comment on 'The Spectral Analysis of Point Processes' by M.S Bartlett," Journal of the Royal Statistical Society. Series B 25.

Besag, J. and P.J. Diggle 1977. "Simple Monte Carlo Tests for Spatial Pattern," Applied Statistics 26, 327.

Bishop, M.C. 2014. The secret history of the Roman roads of Britain (Barnsley, South Yorkshire).

Black, E.W. 1995. Cursus publicus: the infrastructure of government in Roman Britain (BAR British series 241).

Booth, P. 1998. "Defining small towns in Roman Britain," J. Roman archaeol. 11, 613-23.

Brookes, S. and H.N. Huynh 2018. "Transport networks and towns in Roman and early medieval England: An application of PageRank to archaeological questions," Journal of Archaeological Science: Reports 17, 477-90.

Brughmans, T. 2010. "CONNECTING THE DOTS: TOWARDS ARCHAEOLOGICAL NETWORK ANALYSIS: CONNECTING THE DOTS," Oxford Journal of Archaeology 29, 277-303.

Brughmans, T. and M.A. Peeples 2017. "Trends in archaeological network research: A bibliometric analysis," Journal of Historical Network Research 1, 1-24.

Burnham, B.C. 1986. "THE ORIGINS OF ROMANO-BRITISH SMALL TOWNS," Oxford J Archeol 5, 185-203.

Burnham, B.C. and J.S. Wacher 1990. The small towns of Roman Britain (Berkeley).

Carreras, C. and P. De Soto 2013. "The Roman Transport Network: A Precedent for the Integration of the European Mobility," Historical Methods: A Journal of Quantitative and Interdisciplinary History 46, 117-33.

Carreras, C., P. De Soto and A. Muñoz 2019. "Land transport in mountainous regions in the Roman Empire: Network analysis in the case of the Alps and Pyrenees," Journal of Archaeological Science: Reports 25, 280-93.

de Soto, P. 2019. "Network Analysis to Model and Analyse Roman Transport and Mobility," in Verhagen, P., J. Joyce and M.R. Groenhuijzen (edd.), Finding the Limits of the Limes: Modelling Demography, Economy and Transport on the Edge of the Roman Empire (Cham) 271-89.

Esmond-Cleary, A.S. 2003. "Civil defences in the west under the high empire," in Wilson, P. (ed.), The Archaeology of Roman Towns: Studies in Honour of John Wacher (Oxford) 72-85.

Esmond-Cleary, A.S. 2007. “Fortificacion en la Britannia Romana: '¿defensa militar o monumento civico?'," in Rodrıguez Colmenero, A. and I. Roda de Llanza (edd.), Murallas de 
Ciudades en el Occidente del Impero Romano: Lucus Augusti como Paradigma, Diputacion (Lugo) 155-65.

Fotheringham, A.S. and C. Brunsdon 2004. "Some thoughts on inference in the analysis of spatial data," International Journal of Geographical Information Science 18, 447-57.

Freeman, L.C. 1978. "Centrality in social networks conceptual clarification," Social Networks 1, 215-39.

Frere, S.S. 1984a. "British Urban Defences in Earthwork," Britannia 15, 63.

Frere, S.S. 1984b. "The early development of the cities of roman Britain," Revue Archeologique de Picardie 34, 11-17.

Frere, S.S. 1991. Britannia: a history of Roman Britain (3. ed., extensively rev., reprinted, Pimlico 6).

Gentle, J.E. 2002. Elements of computational statistics (Statistics and computing).

Good, P.I. 2005. Permutation, parametric and bootstrap tests of hypotheses (3rd ed, Springer series in statistics).

Gorenflo, L.J. and T.L. Bell 1991. "Network analysis and the study of past regional organisation," in Trombold, C.D. (ed.), Ancient road networks and settlement hierarchies in the New World (New directions in archaeology) 80-98.

Haynes, I. 2002. “Britain's First Information Revolution: the Roman army and the transformation of economic life," in Erdkamp, P. (ed.), The Roman army and the economy (Amsterdam) 111-26.

Hobley, B. 1983. "Roman urban defences: a review of research in Britain," in Maloney, J. and B. Hobley (edd.), Roman Urban Defences in the West (London) 77-84.

Hope, A.C.A. 1968. "A Simplified Monte Carlo Significance Test Procedure," Journal of the Royal Statistical Society. Series B (Methodological) 30, 582-98.

Kolb, A. 2001. "Transport and Communication in the Roman State: the Cursus Publicus," in Adams, C.E.P. and R. Laurence (edd.), Travel and geography in the Roman Empire (London ; New York) 95-105.

Latora, V. and M. Marchiori 2001. "Efficient Behavior of Small-World Networks," Phys. Rev. Lett. 87, 198701.

Latora, V. and M. Marchiori 2003. "Economic small-world behavior in weighted networks," Eur. Phys. J. B 32, 249-63.

Lewis, J. 2021. "Probabilistic Modelling for Incorporating Uncertainty in Least Cost Path Results: a Postdictive Roman Road Case Study," J Archaeol Method Theory. 
Ligt, L. de and J.L. Bintliff (edd.) 2020. Regional Urban Systems in the Roman World, 150 BCE250 CE (Mnemosyne supplements: History and archaeology of classical antiquity volume 431).

Margary, I.D. 1973. Roman roads in Britain (3rd ed, London).

Millett, M. 1990. The romanization of Britain: an essay in archaeological interpretation (Cambridge [England] ; New York).

North, B.V., D. Curtis and P.C. Sham 2002. "A Note on the Calculation of Empirical P Values from Monte Carlo Procedures," The American Journal of Human Genetics 71, 439-41.

Orengo, H.A. and A. Livarda 2016. "The seeds of commerce: A network analysis-based approach to the Romano-British transport system," Journal of Archaeological Science 66, 21-35.

Östborn, P. and H. Gerding 2014. "Network analysis of archaeological data: a systematic approach," Journal of Archaeological Science 46, 75-88.

Roman Roads Research Association 2021. RRRA Home.

Rust, T.C. 2006. Architecture, economics, and identity in Romano-British "small towns" (BAR international series 1547).

Smith, A. and M. Fulford 2019. "The Defended Vici of Roman Britain: Recent Research and New Agendas," Britannia 50, 109-47.

The Viatores 1964. Roman Roads in the South-east Midlands.

Todd, M. 1970. “The Small Towns of Roman Britain,” Britannia 1, 114.

Turner, R. and C. Jeffs 2017. "An extension of Monte Carlo hypothesis tests," Communications in Statistics - Simulation and Computation 46, 6545-58.

Verhagen, P., L. Nuninger and M.R. Groenhuijzen 2019. "Modelling of Pathways and Movement Networks in Archaeology: An Overview of Current Approaches," in Verhagen, P., J. Joyce and M.R. Groenhuijzen (edd.), Finding the Limits of the Limes: Modelling Demography, Economy and Transport on the Edge of the Roman Empire (Computational Social Sciences) 217-49.

Wacher, J. 1962. "A Survey of Romano-British Town Defences of the Early and Middle Second Century," Archaeological Journal 119, 103-13.

Wacher, J.S. 1975. The towns of Roman Britain (Berkeley). 